\title{
Preparation of Carica Papaya Lipase and its Catalytic Resolution on Flurbiprofen Methyl Ester
}

\author{
Chunyu Li ${ }^{1, a}$, Huiying Lin ${ }^{2, b}$, Wei Zhang ${ }^{3, c}$ and Jiaying $\mathrm{Xin}^{4, \mathrm{~d}^{*}}$ \\ ${ }^{1}$ Key Laboratory for Food Science and Engineering, Harbin University of Commerce, Harbin, China

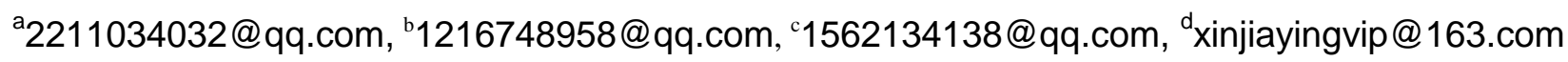 \\ *The corresponding author
}

Keywords: Carica papaya lipase; Flubiprofen; Chiral separation

\begin{abstract}
Carica papaya lipase (CPL) stored in the crude papain was explored as enantioselective biocatalys for the hydrolysis resolution of flubiprofen methyl ester. According to its natural properties, 13 percent of carica papaya lipase was obtained from crude enzyme extraction where the activity of the lipase was $90 \mathrm{U} / \mathrm{g}$. The optimum hydrolysis conditions of carica papaya lipase were as below, the lyophilization time was 8 hours, the reaction temperature was $35^{\circ} \mathrm{C}$, and the $\mathrm{pH}$ was 7.0. Based on the hydrolysis catalyzed by carica papaya lipase, it was found that carica papaya lipase has a good tolerance to the low polar organic solvents. On the basis of single factor experiments the optimal conditions was built when the reaction was carried out in the iso-octane with $10 \mathrm{mg} / \mathrm{mL}$ of flurbiprofen methyl ester, $70 \mathrm{mg}$ of carica papaya lipase, $5 \%$ of the buffer, $150 \mathrm{rpm}$ of the stirring speed, at $35^{\circ} \mathrm{C}$ for 7 days. The maximum conversion was $14 \%$, and the enantiomer excess of product was $87 \%$. Comparison of two methods for flubiprofen resolution indicated that the second resolution method can get a higher optical purity of flurbiprofen than that of the single lipase resolution method.
\end{abstract}

\section{Introduction}

There is a considerable interest in lipase available from the natural sources due to its convenient purification, ample raw materials resource, and competitive advantages in prices [1]. Although lipase from plant seems to be attractive, the low contents and activities of the lipase in seed and grain have limited their usage in large applications. In recent years, carica papaya lipase has been found in crude papain and widely applied on a large scale [2], such as the catalytic resolution of a variety of materials, the modification of oil, the synthesis of short chain alcohol and so on, because of its active, enantioselective and thermally stable characters. Carica papaya lipase integrated closely with the water-insoluble portion of the fiber, which brings about the inconvenience for its separation and purification. However, this makes it a "natural immobilized" lipase[3]. The rapid pace of the development of the chiral drugs and the great disturbance caused by the thalidomide crisis have made so notable effect that scientists have attached importance to how to synthesize optical pure enantiomers [4]. In pharmaceutical industry, optical pure enantiomers have a crucial significance to improve drugs' efficacy and reduce adverse effect. Flurbiprofen is a white crystalline powder with stimulating odor. The major application for flurbiprofen is as non-steroidal anti-inflammatory drug for treating rheumatoid arthritis, osteoarthritis, ankylosing spondylitis, traumatic pain and other pains [5]. However, classical methods for enantioselective resolution often require expensive costs. Therefore, the catalytic resolution of flurbiprofen methyl ester by Carica papaya lipase is of great interest.

\section{Materials and Methods}

Materials. Papaya lipase (Food additives), disodium hydrogen phosphate (Analytical degree), monometallic sodium orthophosphate (Analytical degree), flurbiprofen (Analytical degree). 
Isolation of Carica Papaya Lipase. 50g of crude papain from Biotechnology Company had been enriched prior to isolation by adding $200 \mathrm{~mL} 100 \mathrm{mM}$ phosphate buffer $(\mathrm{pH} 7.5)$ into $1 \mathrm{~L}$ flask. Stired at $4^{\circ} \mathrm{C}$ for $30 \mathrm{~min}$ in ice-water mixture, the flask had been centrifuged at $4{ }^{\circ} \mathrm{C}$ for $10 \mathrm{~min}$ under centrifugal condition at a speed of $9000 \mathrm{rpm}$. The supernatant from the flask had been removed and the precipitation had been collected. Above operation had been repeated 3 times [6]. The collected precipitation had been frozen in refrigerator at $-80^{\circ} \mathrm{C}$ for 10 hours and then lyophilized at the condition of $-43^{\circ} \mathrm{C}$. To determine the activities of the samples and water content in samples, the tests had been carried out at different time during freeze-drying procedure. Freeze dried powder obtained from above operations was CPL enzyme and had been placed in sealed containers with different values of $\mathrm{a}_{\mathrm{w}}$ to balance for 48 hours [7].

Effect of Temperature on the Degree of the Resolution of Flurbiprofen Methyl Ester. 100mg flurbiprofen methyl ester had been sampled and then dissolved in $10 \mathrm{~mL}$ isooctane. $5 \%$ phosphate buffer and 70mg CPL had been added with 150rpm of the stirring speed. Under this condition, the effect of temperature $\left(30^{\circ} \mathrm{C}, 35^{\circ} \mathrm{C}, 40^{\circ} \mathrm{C}, 45^{\circ} \mathrm{C}, 50^{\circ} \mathrm{C}\right)$ on the degree of resolution of flurbiprofen methyl ester had been investigated.

Effect of Stirring Speed on the Degree of the Resolution of Flurbiprofen Methyl Ester. $100 \mathrm{mg}$ flurbiprofen methyl ester had been sampled and then dissolved in $10 \mathrm{~mL}$ isooctane. $5 \%$ phosphate buffer and 70mg CPL had been added at $35^{\circ} \mathrm{C}$. Under this conditions, the effect of speed of the table(100rpm, 150rpm, 200rpm, 250rpm, 300rpm) on the degree of resolution of flurbiprofen methyl ester had been investigated.

Effect of Reaction Time on the Degree o the Resolution of Flurbiprofen Methyl Ester. 100mg flurbiprofen Methyl Ester had been sampled and then dissolved in $10 \mathrm{~mL}$ isooctane. $5 \%$ phosphate buffer and $70 \mathrm{mg}$ CPL had been added at $35^{\circ} \mathrm{C}$ with $150 \mathrm{rpm}$ of the speed. Conversion had been tested every 24 hours. Under this condition, the effect of reaction times on the degree of resolution of flurbiprofen methyl ester had been investigated.

\section{Results}

Influence of Temperature on the Degree of the Resolution of Flurbiprofen Methyl Ester. Increasing temperature could accelerate the positive reaction, but not favorable for the effect of resolution. Excessively high temperature had an effect on the activity of lipase and decreased the selectivity of lipas. Fig 3 showed that the degree of the resolution of Flurbiprofen Methyl Ester was best at $35^{\circ} \mathrm{C}$ where the conversion was $14 \%$ and $e_{\mathrm{p}}$ was $78 \%$. With the improvement of temperature, the conversion was decreased. It means that the activity of lipase had decreased and ee $\mathrm{p}$ had also dropped. Therefore, at this time, selectivity was not best. The optimal resolution temperature was $35^{\circ} \mathrm{C}$.

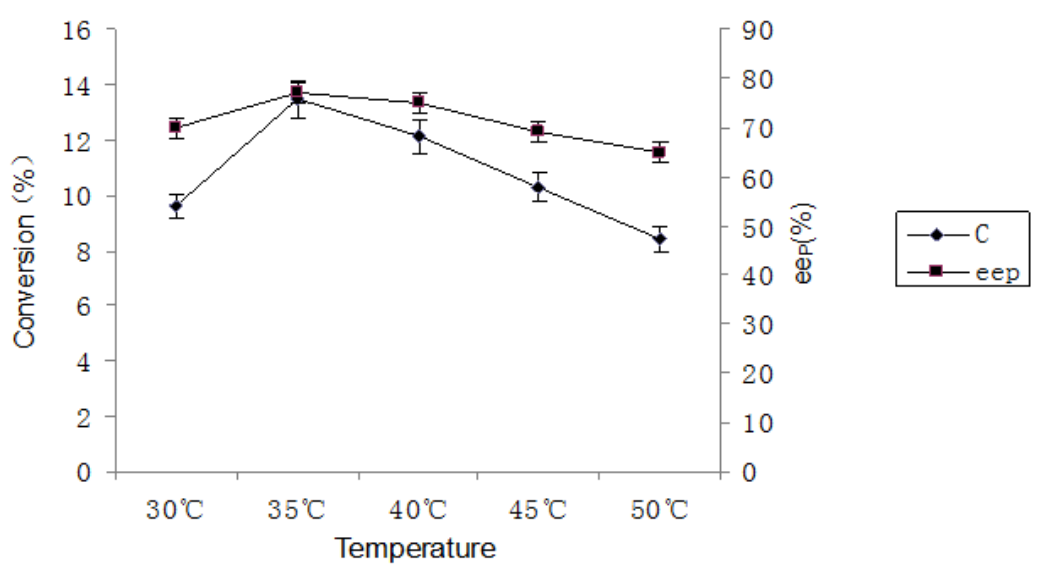

Figure 1. The effect of reaction temperature on the degree of the resolution of flurbiprofen methyl ester 
Influence of stirring speed of the table on the degree of the resolution of flurbiprofen methyl ester. The space of reaction system was very small and the effect point of lipase was the boundary between water and organic solvent. Owing to suspension in the hanging side of the organic solvent, CPL could attach to the wall of the flask and lead to the inactivation of lipase when the speed of the table was too fast. Fig 4 showed that lipase was completely suspended in the solvent and not attached to the wall of the flask when the speed was $150 \mathrm{rpm}$. With the improvement of the speed, lipase accumulated on the wall of flask and the concentration was decreased and $e_{p}$ was relatively stable.

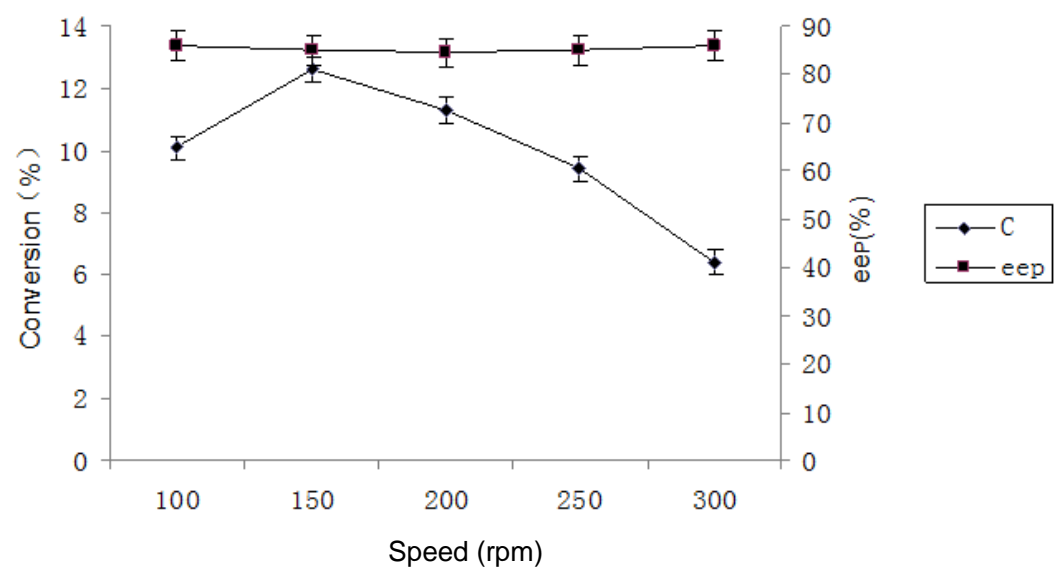

Figure 2. The effect of stirring speed on the degree of the resolution of flurbiprofen methyl ester

Influence of reaction time on the degree of the resolution of flurbiprofen methyl ester. Reaction time is an important factor in the process of catalysis resolution. The more time was, the more reaction was. However, it was not suitable for resolution reaction and reversible process to have more reaction time. Fig 5 showed that: with the increase of time, the rate of conversion was gradual increased in the persistent reaction and the reaction achieved balance for 7 days or so. e $e_{\mathrm{p}}$ was stable from first day to seventh day but obviously decreased at the eighth and ninth days. It means that the resolution of flurbiprofen ester catalyzed by CPL had a good tolerance in isooctane solution, which had many adventages, such as long duration and high selectivity. While the activity of lipase had decreased at the eighth and ninth days, it had a nice effect of resolution. To obtain high enantiomeric purity of (S) - flurbiprofen, the optimal reaction time was 7 days.

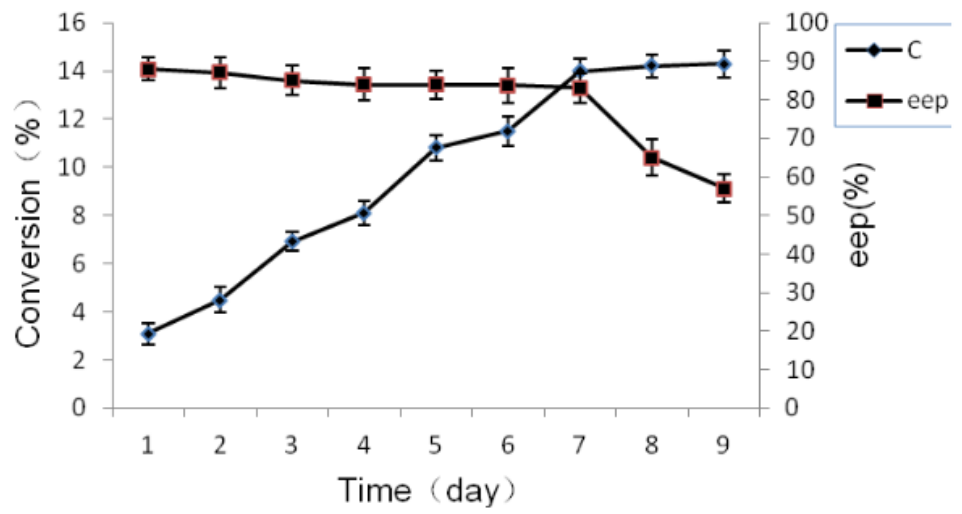

Figure 3. The effect of reaction time on the degree of the resolution of flurbiprofen methyl ester

\section{Summary}

This report mainly studies carica papaya lipase. We get $5.28 \mathrm{~g}$ flurbiprofen methyl ester by usage of some methods. According to some literatures about resolution of chiral drugs catalyzed by lipase, we used CPL to catalyze flurbiprofen methyl ester. And then we did single factors experiment. From the various factors that affected the degree of resolution of flurbiprofen methyl ester showed that: when 
addition of enzyme was $70 \mathrm{mg}$, addition of buffer was $7 \%$, temperature was $35^{\circ} \mathrm{C}$, stirring speed was $150 \mathrm{rpm}$ and reaction time was 7 days, the rate of conversion was $14 \%$ and $\mathrm{ee}_{\mathrm{p}}$ was $87 \%$.

\section{Acknowledgment}

The authors thank the Scientific Research Fund of Heilongjiang Province (GC13C111) for support.

\section{References}

[1] Pengyong You. Preparation, Properties and Application of Carica Papaya Lipase [D]. East China University of Science and Technology. 2012.

[2] Yin Yi, Aijuan Tan. Study on Production Technology of Carica Papaya Lipase [J]. Journal of guizhou agricultural sciences.2000, 28(5): 24-25.

[3] Long Xie, Jiaying Xin, Yan Wang.Application Progress of Carica Papaya Lipase [J]. Journal of Chemical Engineer, 2015, 11:41-44.

[4] Walsh G., Proteins: Biochemistry and Biotechnology, Chichester: John Wiley, 2002; 369-433.

[5] Ching-Shih Chen, Shih-Hsiung Wu, Gary Girdaukas, et al. Quantitative Analyses of Biochemical Kinetic Resolution of Enantiomers-2-Enzyme-Cataly-zed Ester-fications in Water-Organic Solvent Biphasic Systems[J]. American Chemical Society, 1987, 109(9): 2812-2817.

[6] Chang Chunsheng, Tai shauwei. Lipase-catalyzed dynamic resolution of n-aproxen thioester by thiotransesterication in isooctane [J]. Biocheical Engine-ering Journal, 1999, 3(3): 239-242.

[7] Azarkan M, El Moussaoui A, vanwuytswinkel D, Dehon G, Looze Y. Fractionation and purification of the enzymes stored in the latex of Carica papaya. J Chromatogr B. 2003, 790: 229-238.

[8] Villeneuve P, Pina M, Montet D, et al. Carica papaya latex lipase: sn-3 stereoselectivity or short-chain selectivity model chiral triglycerides are removing the ambiguity [J]. J Am Oil Chem Soc, 1995, 72: 753-755.

[9] Gandhi N N, Mukherjee K D. Reactivity of mediumchain substrates in the interesterification of tripalmitin catalyzed by papaya lipase [J]. J Am Oil Chem Soc, 2001, 78: 965- 968.

[10] Erzheng Su and Dongzhi Wei. Production of Fatty Acid Butyl Esters Using the Low Cost Naturally Immobilized Carica papaya Lipase [J]. Journal of agricultural and food. 